\title{
PERMANENT ANTERIOR DISLOCATION OF THE PROXIMAL TIBIOFIBULAR JOINT
}

\author{
P. J. A. MOLITOR, D. J. DANDY
}

From Newmarket General Hospital, Suffolk

\begin{abstract}
We report two patients with permanent dislocation of the proximal tibiofibular joint and no history of trauma. Both needed operation, one for persistent pain and the other for common peroneal nerve involvement, and both had a good result.
\end{abstract}

The superior tibiofibular joint may sublux with "excessive symptomatic anteroposterior motion without frank dislocation" (Ogden 1974), or dislocate after direct or indirect trauma. Dislocations may be anterolateral, posteromedial or superior. Anterolateral is the most frequent, 56 cases having been reported in the literature. (Parkes and Zelko 1973; Ogden 1974; Conforty, Tal and Margulies 1980; Falkenberg and Nygaard 1983; Andersen 1985; Turco and Spinella 1985; Thomason and Linson 1986). Odgen described one patient with subluxation who progressed to complete dislocation, but we were able to find no reference to permanent and complete dislocation without preceding trauma or subluxation.

\section{CASE REPORTS}

Case 1. A 25-year-old woman had developed pain in the left knee from the age of 19 years; this became increasingly severe and was associated with discomfort in the ankle. There was no history of trauma or subluxation.

On examination, the left fibular head was prominent and radiographs showed anterolateral dislocation. At operation, the head of the fibula was exposed through a vertical incision and its proximal centimetre excised subperiostally, leaving the fibular collateral ligament

P. J. A. Molitor, FRCS, Orthopaedic Registrar

Addenbrooke's Hospital, Cambridge CB2 2QQ. England.

D. J. Dandy, FRCS. Consultant Orthopaedic Surgeon

Newmarket General Hospital, Exning Road, Newmarket, Suffolk CB8 7JG, England.

Correspondence should be sent to Mr D. J. Dandy.

(C) 1989 British Editorial Society of Bone and Joint Surgery

$0301-620 \mathrm{X} / 89 / 2055 \$ 2.00$

J Bone Joint Surg [Br] 1989:71-B:240 - 1 . intact. Reduction could not be achieved until the anteromedial margin of the fibular head had been removed.

Symptoms resolved within six weeks, but one year later, the patient had some pain on the lateral side of the thigh, perhaps because the insertion of biceps femoris had been disturbed. The original symptoms did not recur.

Case 2. A 16-year-old apprentice electrician gave a oneyear history of pain in the right knee, with intermittent stiffness of the right ankle and increasing paraesthesia in the lateral aspect of the leg. He had first noticed a swelling on the lateral side of his right knee at the age of 14 years. There was no history of trauma or subluxation.

On examination, the fibular head was found to be dislocated anterolaterally (Fig. 1). There was diminished

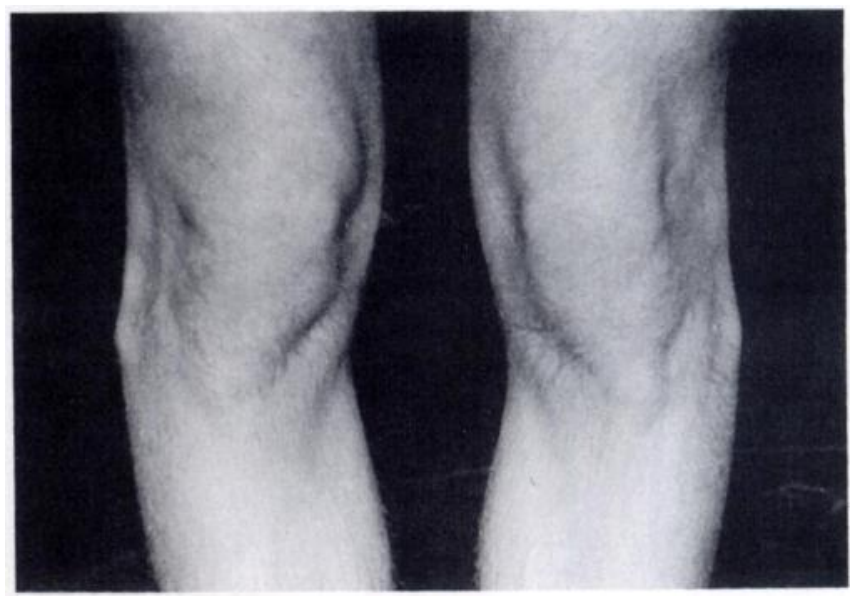

Fig. 1

Case 1. Appearance of the knees from the front showing the prominence of the fibular heads. 
sensibility in the distribution of the common peroneal nerve over the lateral aspect of the right foot and ankle and weakness of dorsiflexion (MRC power 4) in extensor digitorum longus, extensor hallucis longus, and tibialis anterior. The fibular head was exposed through a vertical incision, the proximal centimetre excised, and the fibula reduced. Reduction was not possible until the bone had been resected. The patient had no symptoms in his left leg, although this fibular head also appeared to be dislocated. Symptoms were completely relieved immediately after operation and had not recurred one year later.

\section{DISCUSSION}

Prominence of the fibular head is seen quite often, and some heads may be completely dislocated, but this is seldom associated with symptoms. In our patients the symptoms were enough to justify operation. The dislocations were permanent and irreducible until excision of the proximal centimetre of the fibula allowed reduction of the fibula to a normal position behind the tibia. Symptoms were relieved by the operations.

Common peroneal palsy has been described in patients with subluxation of the fibular head and paraesthesia without motor signs in patients with traumatic dislocation (Ogden 1974) but we can offer no explanation for the progression of the neurological deficit after skeletal maturity in our second patient.

We conclude that permanent dislocation of the fibular head requiring operation is extremely unusual but, when it does occur, the symptoms can be relieved by excision of the proximal centimetre of the fibula.

No benefits in any form have been received or will be received from a commercial party related directly or indirectly to the subject of this article.

\section{REFERENCES}

Andersen K. Dislocation of the superior tibiofibular joint. Injury $1985: 16: 494-8$.

Conforty B, Tal E, Margulies Y. Anterior dislocation of the head of the fibula. J Trauma 1980;20:902-3.

Falkenberg $\mathbf{P}$, Nygaard $\mathbf{H}$. Isolated anterior dislocation of the proximal tibiofibular joint. J Bone Joint Surg [Br] 1983;65-B:310-1.

Ogden JA. Subluxation and dislocation of the proximal tibiofibular joint. J Bone Joint Surg [Am] 1974;56-A:145-54.

Parkes JC II, Zelko RR. Isolated acute dislocation of the proximal tibiofibular joint: case report. $J$ Bone Joint Surg $[A M]$ 1973:55-A :177-80.

Thomason PA, Linson MA. Isolated dislocation of the proximal tibiofibular joint. Trauma 1986;26:192-5.

Turco VJ, Spinella AJ. Anterolateral dislocation of the head of the fibula in sports. Am J Sports Med 1985;13:299-15. 